\section{ON THE ART OF MAKING REFERENCES.}

BY JAMES BLAKE BAILEY, B.A.,

Librarian of the Royal College of Surgeons of England.

THE advice given by the venerable President of Magdalen to Mr. Burgon, "always verify your references;" good and necessary though it is, does not in the present day go quite to the root of the matter. Before the references can be verified they must be quoted, and here is the pitfall into which so many authors stumble. The greatly increased number of journals makes exact references more necessary than ever. By pointing out some of the more common errors a little progress may perhaps be made towards getting uniformity in reference quoting.

The illustrations of bad references given in this paper are from medical and surgical books, and are not imaginary; all of them have been taken from recent publications. Only those persons who are constantly using medical literature can fully appreciate the time that is wasted through bad and incorrect references, and it must be added, as regards some books, through lack of references. It is no uncommon thing to come across such a statement as "Jones's experiments show, etc., etc." To the author who makes this statement it would mean but an infinitesimal amount of time and labour to say where an account of Jones's experiments could be found; but to anyone who wishes to read the original account it often means a great waste of time and display of temper.

One of the first rules for good references is that the title of the book or journal referred to should be given in its original language, and should not be translated. There is often no word in English to exactly represent the one translated, and so endless confusion is caused. The following is an example : "P. Cong. Wiesbaden, vol. 4, pp. 381, 403, Bergmann, 1886, Frimdlander." The P. here stands for Proceedings. This is about as incorrect a reference as can well be imagined; it ought to read thus : "Friedländer, Verhandl. des Congr. für innere Med., 4ter Congr. 1885, p. 403; 5ter Congr., 1886, p. 381." Bergmann is the name of the publisher, and causes confusion by being thus introduced. Examples might be multiplied to any extent, such as "Report of the Jenner Children's Hospital," and "Congrès de la Soc. Allem. de Chir.," both of which titles ought to be in German. To be quite logical in this matter, the name of the author of the paper should be translated as well as the journal from which it is taken, so that Dr. Blanc would appear as Dr. White. The French are the greatest offenders in this matter of translating titles, but the fault is growing in a certain class of English books, those, namely, of authors who copy bibliographies without any verification whatever. Useful as bibliographies are, it is to be feared that they are often appended to a bcok or paper to give an idea of the wide reading of the author; whilst it is patent that the entries are copied wholesale from some Centralblatt or Yearbook, and that many of the books have never been seen by the author in question.

Reference should always be taken from the title pages of books and not from the lettering on the back. Sir Douglas Galton's recent book on Healthy Hospitals is lettered Hospital Construction. In binding the book the present lettering will disappear, and in time to come references to Hosprtal Construction will be meaningless and give much trouble; in fact, they will refer to a book which does not exist. . It is good practice in cataloguing to note such peculiarities as these; a difficulty may often be thus easily cleared up.

A reference which gave me some trouble was Archiv für Hygiene, Band 34. I knew that nothing like that number of volumes had been issued, and was about to search through them all when I remembered that the work containing this reference was done in the College of Surgeons Library; then I saw the mistake. The College set is bound up two volumes in one, and this particular one is lettered 3-4. The reference had been taken from the back of the book, with the result that 34 had been read for 3.4 . Whilst on this head it may be worth while to note another common cause of wrong references when two volumes are bound together. The paper noted is in the second volume, say xiv; the book is opened at the beginning, and the reference is quoted as being in vol. xiii. The moral here evidently is-bind two in one as little as possible.
Another hint to librarians and to those who bind up their journals, may perhaps be allowed here-namely, always to note on the back of a volume any error in the printed numbers on the title. As an example I may quote the Archives Génerales de Médecine; in the seventh series of this journal seven consecutive vols. ( $x x$ to xxvi) are called vol. Xx. A reference, therefore, to seventh series, vol. $\mathrm{xx}$, may be very puzzling unless the error be notified on the back of the set. The plan I adopted in this case was to letter the vols. in their proper order, xxi to xxvi, and to add in the panel, under the number of vol., "on title page vol. xx." Anyone going to the set for vol. $x x$ is by this means at once made aware of the mistake. In sets divided into series care should be taken to quote the series as well as the number of the vol. If there is a continuous numbering in addition to the series it is good practice to give both, thus xlvii (3rd series, 12). This simplifies matters if the set of books used has not both letterings on the backs.

A reference to an abstract of a paper should always state the place where it originally appeared. In an English book I find the following reference, "Wolfenden, Cent. f. Laryng., vol. vi, p. 131." On turning this up a bare mention of Dr. Wolfenden's paper will be found; the real reference is Prac titioner, vol. xxxix, p. 422. A case of this sort not only wastes time, but may hinder a person from consulting the paper he wishes to find. He asks at a library for the Centralblatt fuir Laryngologie and cannot get it, though the Practitioner may be avallable for his use if he only had the reference to it. Some references of this kind are nearly useless; for example, I have before me in a pretentious bibliography a reference to the Report of the Committee of the Clinical Society on Myxcdema, and the only intimation of where this report is to be found is "Berl. klin. Woch., 42."

Reports of societies in weekly journals should never be referred to by the name of the society unless the volume and page of the journal containing the report be also given. This particularly refers to societies which do not issue any separate transactions or proceedings. I have a reference to "Midland Medical Society, February 8th, 1893, Suckling ;" it should be "British Medical Jodrnat, 1893, vol. i, p. 900." The "Midland Medical Society" does not exist as a book, neither does the "Manchester Pathological Society." yet I take from a French book "Soc. Pathol., Manchester, Novembre." The following reference is very inexact : "Clin. Soc., May, 1889," and there is no excuse for $i t$, as the volume containing the report of the session 1888-89 had been issued some time before this reference appeared.

In speaking of the weekly journals I should like to draw attention to the bad habit of quoting only the date of issue; thus "British Medical JodRnal, January 19th, 1895." This necessitates looking through many pages after the volume has been bound, whereas " BRITise Mrdical JodRnal, 1895, vol. $i$, p. 121," is definite, and saves much time and trouble. In passing I would remark that "vol. ii, 1895," is not the same thing as "1895, vol. ii." The former refers to the second volume of a set, published in 1895 , the latter to the second volume for the year 1895 . Some authors mix these up and so cause confusion. The above remark as to the weekly journals will partly apply to some others. For example, the parts of Brain are numbered consecutively on the wrappers only; inside the part there is no mention of this numbering, so that in binding, the numbers on the covers disappear altogether. A reference, therefore, to the number of the part is often troublesome to find; volume and page are the proper things to be recorded in such a case as this.

In Transactions and Journals which do not run with the year, or which make more than one volume in the year, the number of the volume should always be given. as the date alone is no indication of the volume required. Thus, "Path. Trans. 1886," is a bad reference, as both vols. xxxvii and xxxviii contain papers read during that year. The number of the volume is always to be preferred to the date; when space will allow it is well to give both. A word of caution may not be out of place as to inventing a numbering. This sometimes occurs with Journals which go by the year but which have no volume numbering. In binding the first year the binder calls it vol. $i$, and subsequent ones are numbered in continuation. A reference to the volume from a $\varepsilon$ et so lettered causes trouble to persons using one lettered with 
the year only. Binders should never be allowed to put on the back of a book any numbering which does not exist on the title page.

In books where there are two paginations care should be taken to state definitely to which the reference belongs. The Comptes Rendus des Séances et Mémoires de la Société de Biologie is an example; the Comptes Rendus being paged separately from the Mémoires. The following is a good illustration of this, Britise Medical Journal, January 25th, 1892, p. 104, it ought to be, British Medical Journal, 1892, vol. i, EPITOMe, p. 104.

It is an unwise plan to use an editor's name as part of a title, except in rare cases where it is useful for distinguishing between two nearly identical titles. As time goes on and editorial changes are made this kind of reference becomes troublesome. To this rule, as to all others, there are some few exceptions, the most notable, perhaps, being Virchow's Archiv. I saw a reference not long ago to Macmillan's Journal of Anatomy in this case the name of the publisher has been added. The curious part of this is that Messrs. Macmillan gave up publishing the Journal of Anatomy ten years ago.

The question of abbreviation of titles is by no means an unimportant one. Hence we need some approach to uniformity ; the full title of a journal is unnecessary, and greatly adds to the bulk of a book when there are many references. I do not think we could do better than adopt as a standard of abbreviation those used by Dr. Billings in the Catalogue of the Surgeon-General's Library. This book is available in every medical library; the system of abbreviation was well thought out, and has thoroughly stood the test of use. Proper abbreviation is not always as simple as it seems. "Jnl. Anat. Physiol." looks very well, and at first sight seems to denote clearly what is meant. From this reference, however, it is quite impossible to say whether it is to an English, French, or German periodical.

In some foreign books care has to be taken in differentiating between the name of an author and the town where he lives. The "Berliner Klinik" has lately taken to add the town to the author's name. and print them like a compound name. Thus a paper is said to be by Dr. Peyer-Zürich; this only appears on the wrapper; inside the author is described as Dr. Peyer. The above case is perhaps tolerably plain, but there are others where one may easily fall into the trap.

Much might be written as to the incorrect quotation of references, but this is a matter on which it is impossible to lay down rules; nearly all writers grumble at the incorrectness of their brother authors, but very few seem to take much pains to be more correct themselves.

\section{THE QUEEN OF PORTUGAL'S DISPENSARY AT LISBON.}

By JOHN D. GIMLETTE, M.R.C.S., L.R.C.P.LoND., Lisbon, Portugal.

Her Majesty Dona Amelia, Queen of Portugal, stands foremost amongst the reigning sovereigns of Europe as a promoter of philanthropy and as a practical worker in the field of medicine, The interest taken by her in the treatment of diphtheria by the antitoxin method has already been noticed in the British Mrdical Journal. Through the kindness of Dr. Mello Breyner, Physician to Her Majesty, it was my recent privilege to visit the charming little dispensary at Lisbon, known by the name of "Dispensario de Sua Majestade a Rainha," which privilege was subsequently graciously extended by the Queen herself.

This building, like the "Gibert" Dispensary at Havredescribed in the British Medical JouRnal of January 12th -is devoted to the treatment of diseases of children. The dispensary is personally managed by the Queen, who is accustomed to visit it regularly and to assist in the dressing and treatment of surgical cases. On the occasion of my visit Her Majesty arrived in the early morning, attended by a maid of honour, and prepared to attend to the wants of the many starving sick Portuguese children assembled. Her gentle solicitude and ready sympathy to both children and mothers at once won the heart.
It is scarcely possible to exaggerate the wretched circumstances of the 2,000 children who have attended the dispensary since its inauguration on Christmas Day, 1893. The object of the institution-the only one of the kind in Portugal-is not only to satisfy the needs of children under 12 years of age in a medical sense, but to provide them with food, warm clothing, and baths.

The building, which has a very modest exterior, is at Alcantara, the chief centre of the manufactories of Lisbon, and is close to the Palace of Necessidades. It stands in a small garden, which serves as a playground for children in front and as a kitchen garden behind, while its windows command a magnificent view of the river Tagus. The entrance door opens from the garden into a waiting room, which is paved with tiles and provided with benches capable of seating about 50 persons. This communicates with the kitchen, which again opens into a light and airy dining room to accommodate 100 children, to whom free dinners of soup, meat, rice, etc., are given twice a day. Sterilised milk is also supplied. A small and richly-painted figure of the Virgin above the door of this room, as well as a finely-carved crucifix, serve as appropriate and natural ornaments for such an institution in this country.

The patients are received in a small, well-appointed consulting room on the first floor. A waiting room, provided with a balcony and with separate doors for entrance and exit, opens into the consulting room on one side and on the other into a well-lighted and ventilated casualty room, which is one of the largest rooms in the building. It is floored with concrete and the most perfect cleanliness is enforced. Two small operating tables of metal are fixed at either side, and facing one of them is a complete apparatus both forthe sterilisation of surgical instruments and for the distillation and sterilisation of water. A tripod for the application of plasterof-paris jackets to the spine, a screen, and the necessaries for antiseptic and simple dressings, douches, etc., complete the furnishings of the room. Surgical operations which do not require hospital treatment are performed here as well as dressings.

Adjoining is a small but well-equipped apothecary's department. The remaining apartments consist of a room fitted with baths and supplied with gymnastic apparatus, a small office, a pantry, and wardrobe. The sanitary arrangements, water supply, and ventilation are very good, and a carriage, provided by the Queen, is at hand to take such patients as require careful conveyance to their homes.

The honorary professional staff-Dr. Carvalho, who is the Medical Officer of Health for Lisbon, and Dr. Mello Breyner, a Court Physician-visit the dispensary on alternate days of the week.

Scrofula, chronic tuberculous disease of bone and joints, and ophthalmia form the bulk of the diseases treated. During the last year 500 successful vaccinations had been performed.

The nursing staff is under a trained sister of charity, who is assisted by eight others as well as by the ladies who bear the Queen company on her daily visits. It is little wonder that this small institution with its efficient staff of medical men and trained nurses, headed by a gracious and kindly Queen, has proved an unmistakable success, and the spirit of love and goodwill displayed in its management is by no means its least pleasant feature.

Medical Men in PoldTICAL IIFE-According to the Journal of the American Medical Association there is only one instance in the history of the United States of a political office of cabinet rank having been held by a member of the medical profession. Dr. Oliver Wolcott, of Connecticut, was appointed Secretary to the Treasury in succession to $\mathbf{M r}$. Alexander Hamilton, on February $3 \mathrm{rd}, 1795$, The President at the time was General Washington. Dr. Wolcott retained his office under President Jefferson, and he continued to do so uniil May, 1800. Dr. Wolcott had served with great distinction in the War of the Revolution, and had risen to the rank of Brigadier-General.

Presentation.-Mr. Samuel Alexander has, on the occasion of leaving Bulwell to take up practice in London, been presented by his friends 'with a gold watch and chain and purse as a mark of their esteem. Mrs. Alexander was presented with a silver teapot. 